\title{
LA CUESTIÓN TRIBUTARIA AMBIENTAL: ALCANCES Y PERSPECTIVAS
}

\author{
Dora Ayala Rojas ${ }^{1}$ - Juan Carlos Baez ${ }^{2}$
}

\section{Introducción}

Nuestro punto de partida consiste en sostener que el marco referencial del sistema social de Occidente, respondió a una construcción patrimonial de la persona que soslayó - y en algunos momentos ocultó - su dimensión personal; y que, esa situación -filosófica y/o antropológica- tuvo sus consecuencias directas sobre el ambiente, porque llevó a los bienes hacia un punto de tensión tan extrema que exigió una urgente reconsideración de la humanidad como valor en sí; y del ambiente como parte de ese valor. ${ }^{3}$

La mencionada reconsideración se traduce en términos socio económicos, como un pedido concreto: que la naturaleza sea no solo un supuesto de hecho de la norma; y que su aprecio no dependa de su utilidad mercantil concreta, sino que se considere parte de un sistema de vida, lo que implica un cambio en el significado de todos los bienes en general y de los bienes comunes en particular al formar parte de un sistema de derecho, de la ciencia y de la vida, que se llama para muchos, ecológico. ${ }^{4}$

Desde esta posición compleja y pluridimensional, el ambiente impacta sobre todo el sistema y plantea uno distinto. ${ }^{5}$ Todas las disciplinas están convoca-

${ }^{1}$ Doctora en Derecho por la Universidad Nacional de Rosario. Profesora titular de Derecho Financiero y Tributario Cátedra B y Adjunta de Economía Política Cátedra B, en la Universidad Nacional del Nordeste; investigadora categorizada e integrante del registro de expertos CONEAU por la misma universidad.

${ }^{2}$ Especialista en Derecho Tributario por la Universidad de Salamanca, España. Profesor Adjunto de Economía Política Cátedra B. Investigador categorizado de la Universidad Nacional del Nordeste.

${ }^{3}$ Lorenzetti, Ricardo (2008). Teoría del derecho ambiental, buenos aires, la ley, prefacio.

${ }^{4}$ Rodríguez, Carlos (2005). Derecho ambiental argentino, Corrientes, Moglia, pág. 19, describe la discusión de los significantes: ambiente, ecología y derecho.

${ }^{5}$ Wark, Julie (2011). Manifiesto de derechos humanos, Madrid, Barataria, pág. 7. 
das, como el derecho, la economía, la sociología, la antropología, la ciencia política, las finanzas; y tantas más. En lo que respecta al derecho, participa de la cuestión ambiental desde sus esferas pública y privada, cada vez más conectadas entre sí por fuentes y principios, ${ }^{6}$ Tanto es así, que la frontera entre ambos se hace difusa y se expresa cada vez más en un sistema articulado que sostiene el todo pero se integra en partes. ${ }^{7}$

Con esta mirada es que venimos a dar cuenta y a poner en común, algunos de los resultados obtenidos durante la investigación del proyecto acreditado de la UNNE: "Los tributos como instrumentos económicos de protección ambiental" que desde el año 2009 y hasta el 2012, se ha nutrido con el trabajo de un equipo de investigadores de formación interdisciplinar, que le dio su propia identidad como producto común por sobre las disciplinas de cada uno; tal como deberían ser, a nuestro modo de ver, los abordajes investigativos en el complejo mundo de hoy. ${ }^{9}$

La estrategia metodológica decidida puede sintetizarse en tres puntos fuertes:

a. Partió desde la especialidad tributaria, no ambiental, pero reconociendo la necesidad de la integración entre ellas; y a su vez, de ellas con otras. Tal integración -no yuxtaposición-implica la conservación de las identidades disciplinares, expresadas en sus puntos de partida, pero enfocadas en la construcción del nuevo renovado objeto común: los tributos ambientales.

b. Tuvo en cuenta el contexto, tanto porque sabemos que cualquier análisis debe partir de la realidad en que se ubica, como también por nuestro convencimiento que todo saber es situado, contextualizado, vivido en sociedad; nuestra sociedad suramericana. Insistimos en este argumento por considerarlo útil para superar la construcción tradicional de saberes compilados, apilados y proyectados como válidos para cualquier realidad.

${ }^{6}$ Lorenzetti Ricardo (1995). Las normas fundamentales de derecho privado), Santa Fe, Rubinzal Culzoni, pág. 42.

${ }^{7}$ Ciuro Caldani Miguel A. (2007). Las partes y el todo en la teoría trialista del mundo jurídico, Rosario, Fundación para las Investigaciones Jurídicas, pág. 37.

${ }^{8}$ PI No g 004/08, Resolución n 831/08 c.s. UNNE.

${ }^{9}$ Ander Egg, Ezequiel (2006). Métodos y técnicas de investigación social, Buenos Aires, Lumen, pág. 79. 
c. Fue de carácter instrumental y dinámico, no enfocó la identificación conceptual de los tributos, que todos en general en mayor o menor medida conocemos; sino más bien, se propuso valorar un aspecto mucho más práctico y por tanto decisivo para la aceptación o el rechazo del tributo ambiental, esto es, su finalidad; o lo que es lo mismo, preguntarse:

\section{¿Por qué y para qué pueden ser usados los tributos ambientales?}

Es obvio que el enfoque reconoce la necesidad de una base conceptual, pero también con la misma solidez, requiere de habilidades que traduzcan "modos de hacer" la cultura tributaria, para no quedar solamente en un concepto construido, sino que sea también un concepto actuante, situante, competente; en la convicción que solamente así, podremos dar cuenta de una cultura tributaria real, en busca del tan ansiado desarrollo, ${ }^{10}$ considerado este, en íntima ligazón con la intervención estatal.

Durante el trayecto investigativo, dividimos la tarea en dos etapas. La primera, para indagar sobre las medidas de intervención en general y la segunda, enfocada en los tributos.

\section{Desarrollo}

\section{Medidas fiscales de intervención ambiental en general}

Las primeras dificultades a vencer, fueron las tareas clasificatorias de las medidas fiscales que pueden ser usadas por el Estado como modo de intervención ambiental. Quedó claro que la literatura de la especialidad, ${ }^{11}$ no siempre separó con nitidez, los tributos de otras medidas similares.

${ }^{10}$ Ayala Rojas, Dora y Baez, Juan C. (2009). Los tributos ambientales, en revista de las $42^{\circ}$ Jornadas de Finanzas Públicas, organizadas por la Facultad de Ciencias Económicas de la Universidad Nacional de Córdoba, en Ciudad Universitaria, 16 a 18 de agosto de 2009, pág. 16-20.

${ }^{11}$ Oliva Pérez, Nicolás; Rivadeneira Alava, Ana; Serrano mancilla, Alfredo y Martín Carrillo, Sergio (2011). Impuestos verdes: ¿una herramienta para la política ambiental en Latinoamérica?, publicación virtual de la fundación Friedrich Ebert Stiftung, el proyecto regional de energía y clima de ecuador y la universidad pablo de Olavide de Sevilla, disponible en www.library.fes.de/pdf-files/bueros/quito/08160-20110603pdf (08-07-2013) 
Por esa razón, nuestros primeros resultados parciales se centraron en poner en común que los instrumentos fiscales de intervención económica provienen de distintas disciplinas ${ }^{12}$ con sus aspectos favorecedores y conflictivos, pero siempre integradores. Así por ejemplo, en la ciencia de la administración, la economía, las finanzas públicas, las más reconocidas son: la regulación, el acuerdo de comercialización, las ayudas (subsidio o subvención), el tributo.

La regulación es la medida más antigua y más frecuentemente utilizada. Se instrumenta jurídicamente a través del derecho administrativo mediante directivas, que obligan en cuanto a los resultados, pero dan libertad a los Estados miembros en cuanto a la forma concreta de llevarlos a cabo. Es de aplicación entre los miembros de la Comunidad Europea.

Sus debilidades principales derivan de: las dilaciones o bloqueos provocados por el conflicto entre los derechos nacionales o internos y los comunitarios; y del desigual impacto de los niveles de competitividad entre regiones/jurisdicciones.

La regulación implica intervenciones estatales directas para introducir limitaciones al desarrollo de actividades consideradas perjudiciales para el ambiente, de modo que según los casos, pueden resultar prohibidas, sujetas a autorización administrativa previa, o condicionadas a determinados estándares técnicos.

Como ejemplo, podemos mencionar las medidas sobre cambio climático y contaminación atmosférica, que se establecen mediante directivas sobre: calidad del aire, valores límites de sustancias contaminantes y/o limitación directa de emisiones. También las directivas sobre contaminación de aguas.

Los acuerdos de comercialización, o mecanismos para el desarrollo limpio (artículo 12 del Protocolo Kioto) constituyen un modo particular de negociación, mercantil o sinalagmático, provienen en consecuencia del derecho empresarial.

Suponen que los países desarrollados y las empresas privadas (Anexo I del Protocolo de Kioto) que inviertan en proyectos de reducción o mitigación de emisiones contaminantes en países en vías de desarrollo o emergentes (no incluidos en el Anexo I del Protocolo de Kioto) recibirán certificados de reducción de emisiones contaminantes -bonos de carbono- a cambio de inversión en tecnolo-

${ }^{12}$ Reafirmando nuestra posición de construcción del conocimiento mediante el trabajo colaborativo entre disciplinas, puede verse Ayala Rojas, Dora E. (2011). El derecho ante los desafíos de la globalización, en actualidad y prospectiva, revista de la facultad de ciencias económicas de la UNNE, n 7, Resistencia Chaco, Iberia, pág. 105-122. 
gías limpias en estos países. Los bonos son más baratos así que si los obtuvieran en sus mercados y los usan para completar las metas de reducción a las que se han comprometido. Se discute si implican un avance en la determinación de las responsabilidades “comunes pero diferenciadas" que en el sistema argentino, exige la Ley General del Ambiente $N^{\circ}$ 25675. A nivel regional -América del Sur-y en definitiva, son polémicos por las características culturales que están en juego (modos de negociación entre autoridades fiscales, empresas contaminantes, particulares, que refieren elevados niveles de desigualdad y consiguientes dificultades para la actuación de los mecanismos de control).

Las ayudas. Llamadas por nuestra doctrina nacional subsidios o subvenciones- tienen el propósito de contribuir ${ }^{13}$ a la reducción de obstáculos para la adopción de normas ambientales, que implican costos materiales y de adaptación de las empresas, incentivando a estas a mejorar sus niveles de protección ambiental, si es posible, más allá de lo establecido por las normas.

Las ayudas tienen su fundamento en la idea de asumir en cooperación y colectivamente, parte de los costos ambientales, en búsqueda prospectiva de beneficios significativos para el conjunto social (inversiones, adaptaciones del aparato productivo, divulgaciones de resultados, asesoramiento, desgravaciones, etc.)

Las cuantías de las ayudas están en relación con la actividad, con la finalidad, con las características de las empresas ayudadas, con las regiones en que se ubican, con los consumidores finales, entre otras dimensiones.

Su valor positivo descansa en que reflejan mejor el carácter preventivo y que se apoyan en valores: la solidaridad, la cooperación, el interés colectivo, etc.; y han adquirido protagonismo en los actuales proyectos de gestión medioambiental de los países de América del Sur.

\section{Medidas fiscales de intervención ambiental en especial: los tributos}

En el ámbito de las finanzas públicas y la tributación -con sus despliegues jurídicos: el derecho financiero y el derecho tributario- el interés por el ambiente se hizo muy presente durante la década de los noventa para financiar los

${ }^{13}$ Villamil serrano, armando y Maties García, Joan (2011). Política económica del medioambiente, Madrid, Ramón Areces, pág. 44. 
daños derivados de las actividades contaminantes. ${ }^{14}$ Para ello se recurrió al soporte teórico de la finalidad extra fiscal del tributo, al principio de controvertida aceptación en la doctrina pero que luego se abrió paso acompañando la participación estatal cada vez más activa en la economía. ${ }^{15}$ La finalidad recaudatoria tuvo así un complemento de distribución cada vez más significativo con exenciones, desgravaciones, créditos beneficios; o su contrapartida: el aumento de alícuotas, pérdida o reducción de beneficios, etc. Paliar necesidades sociales, corregir desequilibrios regionales, incentivar, de alentar o desalentar actitudes a diferentes niveles de consenso, se constituyeron en las razones determinantes de las mencionadas medidas intervencionistas. ${ }^{16}$

Aceptada la naturaleza extra fiscal de la tributación y siguiendo la clasificación generalmente aceptada, ${ }^{17}$ los tributos ambientales pueden asumir la forma de impuestos, tasas y contribuciones.

Los impuestos son los que más dificultades conceptuales presentan para el caso, porque la cuestión ambiental es resistente al principio de la capacidad contributiva, principal distintivo de la figura, consagrada por su fuente alemana. ${ }^{18}$ Recordemos que la capacidad contributiva es el límite material el impuesto, lo legitima; porque implica la exteriorización de una renta, de un patrimonio o de un consumo. La relación de ese hecho -creado por ley- con una persona -sujeto pasivo- da nacimiento a la obligación tributaria.

Desde este punto de vista, el impuesto ambiental no se sustenta directamente en la capacidad contributiva, porque no refiere a ninguna manifestación

${ }^{14}$ Fitoussi, Jean Paul y Laurent Éloi (2011). La nueva ecología política. economía y desarrollo humano, buenos aires, capital intelectual, pág. 13. Cafferatta Néstor (2009), Teoría general de la responsabilidad civil ambiental, en Lorenzetti Ricardo (coord.), Derecho ambiental y daño, Buenos Aires, La Ley, pág.11.

${ }^{15}$ Díaz, Vicente (2004). El carácter extra fiscal de la tributación y la imposición medioambiental, en Díaz Vicente (dir.), Tratado de tributación, tomo II, "Política y economía tributaria”, Vol. I, pág. 594-622.

${ }^{16}$ Corti, Horacio (2007), Derecho constitucional presupuestario, Buenos Aires, Lexis Nexis, pág. 18.

${ }^{17}$ Lascano, Marcelo (2003). El sistema tributario, alcances y propuestas, en Lascano, Marcelo (dir.), Impuestos. Doctrinas fundamentales. 1942-2002, Buenos Aires, La Ley, pág. 692-696-

${ }_{18}$ Antonio, Arnaldo (2007). Impuestos ambientales, Buenos Aires, Osmar D. Buyatti, pág., 195. 
directa de renta y /o patrimonio, quedando la posibilidad de manifestación indirecta de consumo. ${ }^{19}$

En la teoría, esta circunstancia dio lugar a dos posiciones:

1. Por un lado quienes refuerzan la caracterización tradicional, expresan que hay capacidad contributiva de manera indirecta, ya que quien contamina supone el ejercicio de alguna actividad económica y por lo tanto se trataría de un impuesto indirecto al consumo. Este rasgo no favorece a la creación de la figura pues si carácter traslativo, haría recaer los efectos distorsivos sobre los que menos tienen.

2. Por el otro, quienes consideran que por su finalidad extra fiscal constituye una excepción al principio de capacidad contributiva, que es sustituido por el principio contaminador-pagador, del derecho ambiental.

El principio “quien contamina paga”, es receptado por la Comunidad Europea y también por la Declaración de Río, $1992^{20}$-Hoy Río +20-, que pone en primer plano, grava, la conducta contaminante: "con el objetivo de internalizar los costos ambientales mediante el fomento de instrumentos económicos, teniendo en cuenta el interés público y sin distorsionar el comercio y las inversiones internacionales”.

Estrictamente, el hecho imponible es la actividad contaminante que se grava de acuerdo a la magnitud del perjuicio (pero si no tenemos capacidad contributiva, se torna difícil la cuantificación del tributo, en consecuencia los indicadores que se sugieren son difusos, como la prudencia, la proporcionalidad, la moderación, etc.). Este rasgo permite el afianzamiento de la teoría del daño del derecho privado y excluye la acción de política pública estatal, que tiene importantes consecuencias con respecto a la consideración patrimonial de los bienes comunes y aun de su ponderación judicial.

En cuanto a su estructura normativa, la dimensión ambiental tiene como base el artículo 41 de nuestra C.N. reformada en 1994, que establece: la garantía de protección, las competencias entre Nación y Provincias y la prohibición

${ }^{19}$ Aiunzúa, Sebastián (2009). Los impuestos ambientales como instrumentos contra el cambio climático, publicación electrónica de la fundación Terram, disponible en www.terram.cl/ index (09-07-2013)

${ }^{20}$ Documento disponible en www.bioculturaldiversity.net (09-07-2013) 
de ingresar residuos peligrosos. ${ }^{21}$ En lo que atañe a nuestro enfoque tributario, la Constitución establece que la Administración y la Jurisdicción ambiental son provinciales; y la Legislación es prioritariamente federal y subsidiariamente local. A esto se agrega que por Ley Convenio de Coparticipación ( $\left.\mathrm{N}^{\circ} 23548\right)$ los municipios están obligados por los regímenes a los que se han adherido sus respectivas provincias. ${ }^{22}$

En consecuencia, en nuestro país la posibilidad de crear tributos ambientales puede darse en los tres niveles de gobierno.

Las legislaciones provinciales que regulan impuestos para la protección ambiental, los relacionan, en su mayoría, con: la generación de residuos sólidos y urbanos, domiciliarios y especiales, como en la provincia de Buenos Aires; los productos forestales derivados de la extracción de bosques fiscales o particulares, como en la provincia de Salta; el uso de energías renovables, como en la provincia de Santa Cruz. ${ }^{23}$

Mención aparte merece la situación de la Ciudad Autónoma de Buenos Aires, donde en el año 2010 se incorporó a su Código Fiscal ${ }^{24}$ un título específico que se denominó “Gravámenes Ambientales” y que sigue los lineamientos que en la materia regula la Comunidad Europea.

El título comprende dos capítulos, que legislan sendos impuestos. Ellos son: Impuesto a la generación de residuos sólidos urbanos húmedos no reciclables (papel, cartón, alimentos) por particulares, comercios e industrias y producidos en cierta cantidad (hay un mínimo exento). La liquidación la realiza el propio contribuyente incluido en el padrón confeccionado por la autoridad ambiental y sin perjuicio de las facultades de verificación posterior por el gobierno de la Ciudad.

Impuesto a la generación de residuos áridos y afines (escombros, tierra) que se origina usualmente por remodelaciones y/o demoliciones. El código fiscal establece como requisito previo a la presentación de los planos de obra o demolición, el pago del impuesto. La base imponible es el costo del metro cuadrado de la obra a remodelar o demoler, según el

${ }^{21}$ Sabsay, Daniel (2005). Derecho constitucional, Buenos Aires, La Ley.

${ }^{22}$ Spisso, Rodolfo (2000). Derecho constitucional tributario, Buenos Aires, Depalma, pág. 13.

${ }^{23}$ Tal como se desprende de los códigos fiscales y legislación complementaria, del as jurisdicciones respectivas. 
caso. Si se efectuara una reutilización de residuos áridos, se puede solicitar la exención.

Las tasas no pertenecen al mundo de la capacidad contributiva sino al del beneficio, acordes con su fuente, el derecho anglosajón. Son importantes como fuente de recursos de las jurisdicciones locales, esto es, de los municipios, ${ }^{25}$ por una antigua tradición -hoy superada-que sostenía la imposibilidad de los municipios para cobrar tributos.

En la práctica, estas figuras tributarias responden más a finalidades recaudatorias que ambientales, sin perjuicio que algunos municipios han comenzado tareas de divulgación y debate de las llamadas tasas ecológicas, que se cobran como adicionales de las retributivas de servicios (por ejemplo, en los municipios de La Plata, Salta, Río Tercero, ${ }^{26}$ entre otros.).

Las más generales refieren como hechos imponibles a: la gestión y tratamiento de residuos (Salta, Bariloche, Rafaela); la extensión de certificados para transportar y manipular residuos peligrosos (Comodoro Rivadavia);la generación de residuos patógenos (San Francisco, Córdoba); el control de efluentes (Villa Mercedes, San Luis). ${ }^{27}$

Si bien existen otras también de uso común, como las tasas por distribución de agua potable o de seguridad e higiene, que pueden contener aspectos ambientales, entendemos que funcionan en realidad como tasas retributivas de servicios que en el mejor de los casos, conllevan algún control ambiental de modo subsidiario, pero no con efecto directo de prevención o protección del ambiente.

En cuanto a las posibilidades de aplicación de las tasas, consideramos que la cuestión tributaria municipal debe ser remarcada hoy muy especialmente y en todos los foros posibles, por el auge de la llamada “explosión urbana horizontal”. ${ }^{28}$

${ }^{24}$ Código Fiscal de la CABA.

${ }^{25}$ Vargas Fernández, J. C. (2011). Sustentabilidad organizacional para el desarrollo ambiental y económico el caso de microempresas en San Sebastián del Sur, en administración y ciudadanía, revista de la escuela gallega de administración pública, vol. 6, n 1 , Santiago de Compostela, Xunta de Galicia, pág. 57-76.

${ }^{26}$ Según códigos fiscales y legislación complementaria de las mencionadas jurisdicciones.

${ }^{27}$ Id. nota anterior.

${ }^{28}$ Vercher Noguera, Antonio (2010). Los efectos de las políticas urbanísticas sobre el territorio y el medio ambiente, en revista gallega de la administración pública, $n^{\circ} 40$, Santiago de Compostela, Xunta de Galicia, pág. 285-306. 
Este fenómeno, se caracteriza por la expansión horizontal -de allí su nombre- de las grandes ciudades, que invaden los territorios de sus alrededores, reflejando un nuevo rostro de la globalización. No es la población rural la que va a la ciudad sino a la inversa, es la población de la ciudad la que va al entorno rural. Este proceso de conurbanización crea espacios híbridos: semi-rurales o semiurbanos, de rasgos propios, viejos y nuevos, donde la tributación ambiental puede y debe notarse, en un espacio de reasignación de significados de lo territorial y de revalorización del gobierno local, enfoque que necesita considerar otros papeles de los gobiernos locales, acompañando la tradicional provisión de los servicios básicos. Y las tasas ecológicas, pueden hacer un aporte significativo.

Las contribuciones llamadas especiales, como la de mejora, tienen la misma naturaleza que las tasas. Requieren para su configuración de la obtención de una ventaja particular -beneficio- derivada de la realización de una obra pública. A partir de ella, la doctrina italiana, en particular a partir de los textos de A.D. Giannini (1938) señaló la posibilidad de otras figuras por analogía y contraste con ella, que si bien no llamaron todavía ambientales, son muy cercanas.

Giannini expresa al respecto, que hace falta estudiar también la prestación debida por quienes, como consecuencia de las cosas que poseen, o del ejercicio de una industria, comercio o cualquier otra actividad, provocan un gasto o el aumento del gasto, por parte del ente público.

La idea de la contribución por gastos ambientales tiene por el trabajo de la doctrina italiana, una vía para ser construida desde este paralelo con la contribución de mejoras, aunque en principio con efecto ex post, como una contribución de perjuicio. Así la refiere la doctrina española, en especial la Escuela de Salamanca y también la mejicana.

En este marco, la contribución debería pagarse como consecuencia de una actividad contaminante que requiera efectuar un gasto público reparador. Consideramos que ese carácter no permitió su mayor difusión, pero demuestra el antiguo interés por la figura, abonando la construcción desde la perspectiva civilista, de la responsabilidad por daño ambiental, hoy gran protagonista de este nuevo escenario disciplinar.

\section{Conclusiones}

Valorando la posibilidad de aplicación concreta de estas figuras, objetivo final del proyecto, nuestras conclusiones pueden agruparse en tres líneas, que resaltan las dificultades y fortalezas posibles; y son: 
Teóricas: En lo que respecta a los tributos, la principal dificultad de los impuestos es la incorporación de la capacidad contributiva, que hacen difusa la cuantificación de la base imponible El principio contaminador pagador es contradictorio al derecho tributario, pues el mejor tributo es el que no se paga. Quedan excluidas de esta dificultad, las tasas y las contribuciones especiales, que no responden a la capacidad contributiva y tienen estructuras más asimilables para el mercado. En lo que respecta a las Ayudas, representan actualmente el modo más asequible de protección ambiental. Los otros mecanismos, a nuestro criterio, no son los mecanismos de protección más favorables.

Económicas: En América Latina hay una posición garantista de protección ambiental, de contenido constitucional pero con escasa creación efectiva de tributos ambientales, lo que obedece en gran medida a que el sector privado los ve como fuentes de costos adicionales que frenan el crecimiento. Esta situación es paradigmática en América Latina y debiera ser objeto de fortalecimiento de las políticas públicas.

Políticas: La consideración ambiental a nivel municipal -que podría comenzar con los residuos- sería estimulante para fortalecer la dimensión local de instituciones y culturas, así como favorecer el reconocimiento de sus propias particularidades y problemas. Haciendo frente de esta manera a la dimensión difusa de lo externo y global, podrían conseguirse acuerdos que protejan los intereses comunes -como el ambiente- de las comunidades pequeñas. 